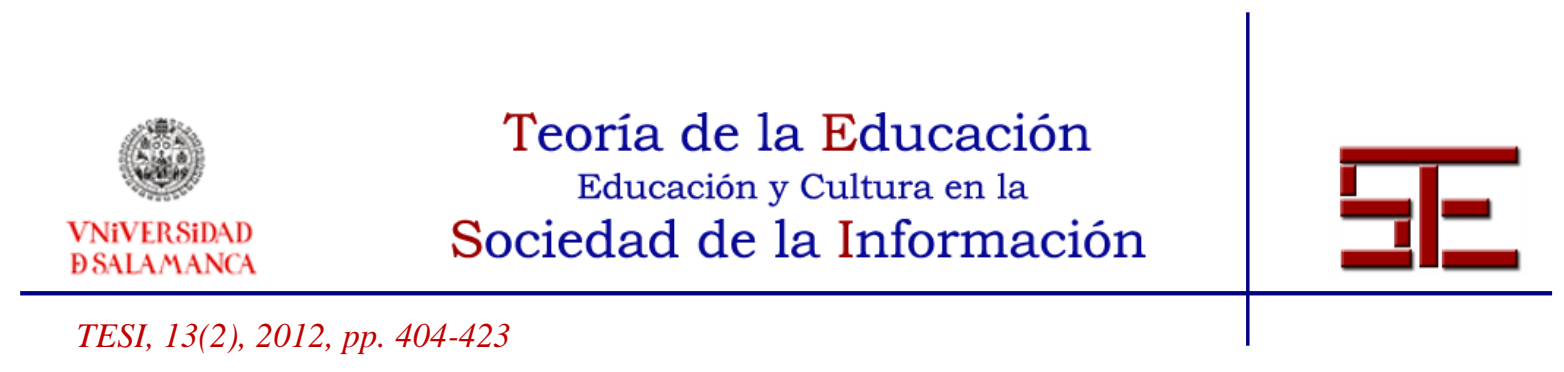

\title{
EL POTENCIAL PEDAGÓgICO DE LA TECNOLOGÍA: DESARROLLAR COMPETENCIAS Y FAVORECER LA AUTONOMÍA $Y$ LA RESPONSABILIDAD EN EL ALUMNADO
}

Resumen: Las mejoras que se han producido en las últimas décadas en el ámbito de las Tecnologías de la Información y la Comunicación se han dejado sentir con fuerza en las instituciones educativas. Además de sus (re)conocidas ventajas desde un punto de vista instrumental, administrativo o de gestión, hemos asistido a una ampliación sin precedentes de los entornos de interacción social y a la construcción de nuevos escenarios de aprendizaje.

Es por ello que nuestro propósito en este trabajo no es otro que analizar los beneficios que puede suponer la tecnología en el aprendizaje de los estudiantes haciendo especial hincapié no sólo en el potencial de estos soportes para favorecer la autonomía y responsabilidad del alumnado en el proceso de enseñanza-aprendizaje, sino también en sus posibilidades para el desarrollo de competencias de corte intercultural.

Entre las conclusiones destacamos sobremanera dos cuestiones: de una parte, la urgencia de apurar la preparación del profesorado en el aprovechamiento de la potencialidad pedagógica de los soportes digitales $\mathrm{y}$, de otra, la necesidad de profundizar en el conocimiento de los efectos que, a largo plazo, puede conllevar el uso de las tecnologías digitales en los comportamientos y en las formas de relación de nuestros alumnos.

Palabras clave: tecnología; escenarios de aprendizaje; interacción social; competencias; interculturalidad.

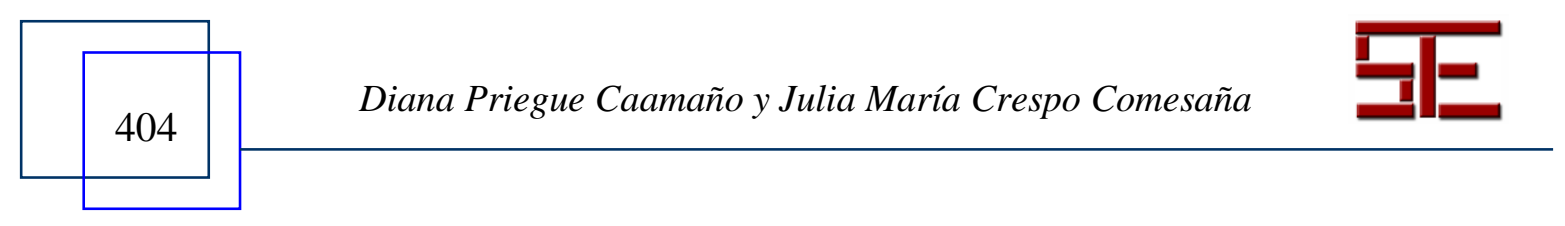




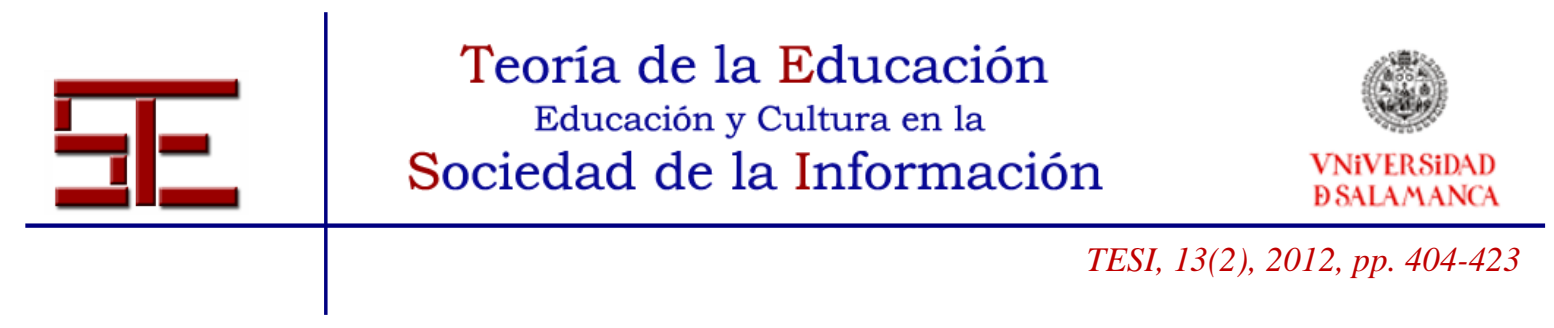

\section{THE EDUCATIONAL POTENTIAL OF TECHNOLOGY: DEVELOPING SKILLS AND PROMOTING STUDENTS' AUTONOMY AND RESPONSIBILITY}

Abstract: The improvements carried out in the last decades in the field of Information and the Communication Technologies are significantly perceived in the educational institutions. Besides the well-known advantages from an instrumental, administrative or managerial point of view, we assist to unprecedented extension of new possibilities of social interaction as well as to the creation of new learning contexts.

Thus, this work is aimed at analysing the benefits that technology can provide in the students' learning process, making special emphasis not only on the potential of these resources to favour students' autonomy and responsibility in the teaching-learning process, but also on their possibilities for the development of intercultural competences. Among the conclusions, we mainly stand out two issues: on the one hand, the urgency to improve teachers' preparation, to make the most of the pedagogical potential of the digital resources and, on the other hand, the need to deepen in the knowledge of the effects that, on a long-term basis, may involve the use of digital technologies in our students' way of behaving and of mixing with each other.

Keywords: technology; learning contexts; social interaction; competences; intercultural.

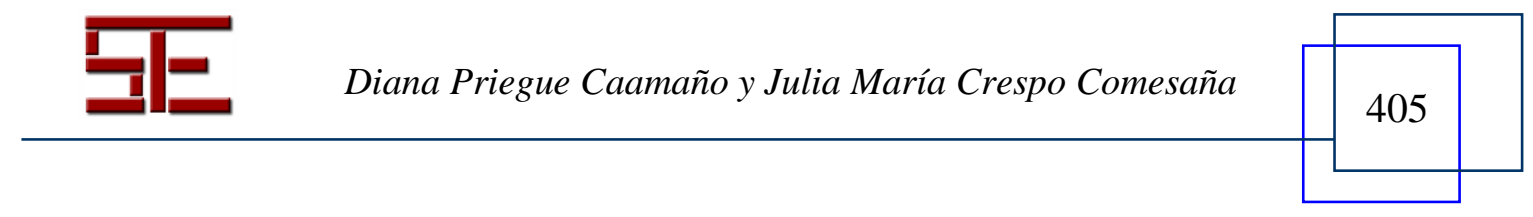




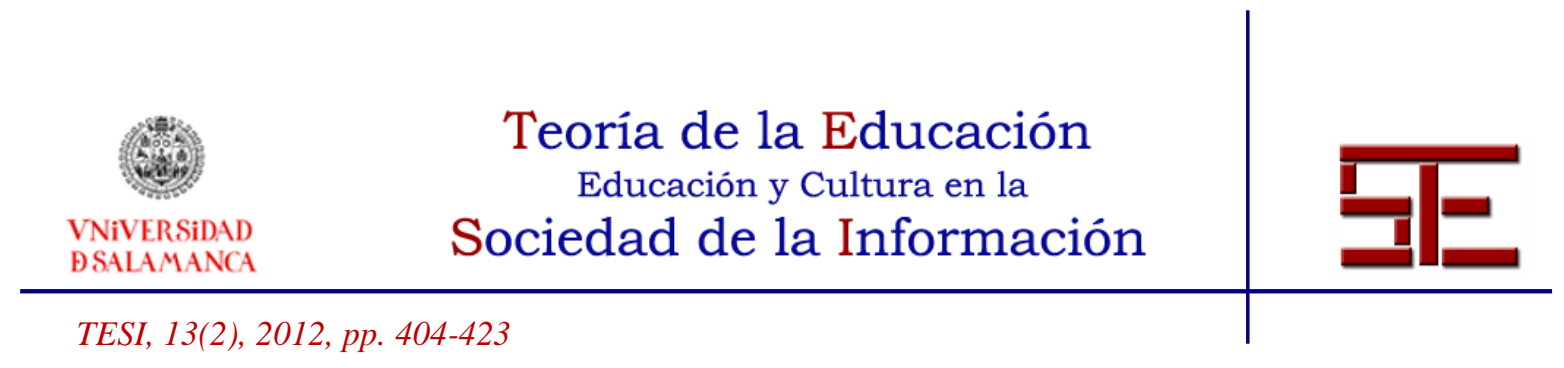

\title{
El POTENCIAL PEDAgógico de la TeCnOlogía: desarrollar COMPETENCIAS Y FAVORECER LA AUTONOMÍA Y LA RESPONSABILIDAD EN EL ALUMNADO
}

Fecha de recepción: 20/09/2011; fecha de aceptación: 20/10/2011; fecha de publicación: 26/07/2012

\author{
Diana Priegue Caamaño \\ diana.priegue@usc.es \\ Universidad de Santiago de Compostela \\ Julia María Crespo Comesaña \\ juliamaria.crespo@usc.es \\ Universidad de Santiago de Compostela
}

\section{INTRODUCCIÓN}

Las últimas décadas de la pasada centuria han marcado el inicio de la denominada revolución tecnológica, un fenómeno global que, en el marco del proceso de reestructuración del sistema capitalista, ha sido el motor de una profunda transformación con claras repercusiones para la sociedad en su conjunto y, de manera particular, para las instituciones educativas.

Sin lugar a dudas, el aprovechamiento de las ventajas que ofrecen las Tecnologías de la Información y la Comunicación (TIC) en la educación puede significar el fin de muchas de las limitaciones que hasta el momento han afectado a las instituciones educativas, pero también es cierto que plantean nuevas exigencias que es preciso atender con urgencia. Así es que, además de sus (re)conocidas ventajas desde un punto de vista instrumental, administrativo o de gestión, las TIC suponen una ampliación sin precedentes de los entornos de interacción social y la construcción de nuevos escenarios de aprendizaje. Y en lo que tiene que ver con los desafíos, entre los más importantes se sitúan los relacionados con el cambio que se ha producido en las prioridades de los sistemas educativos, un cambio que ha adquirido una mayor visibilidad con el impacto de la tecnología. El objetivo de la escuela ya no es proporcionar aquellos conocimientos que se consideran imprescindibles para ser miembro de la sociedad actual. La finalidad última es preparar al alumnado para que, de manera autónoma, pueda seguir aprendiendo a lo largo de la vida.

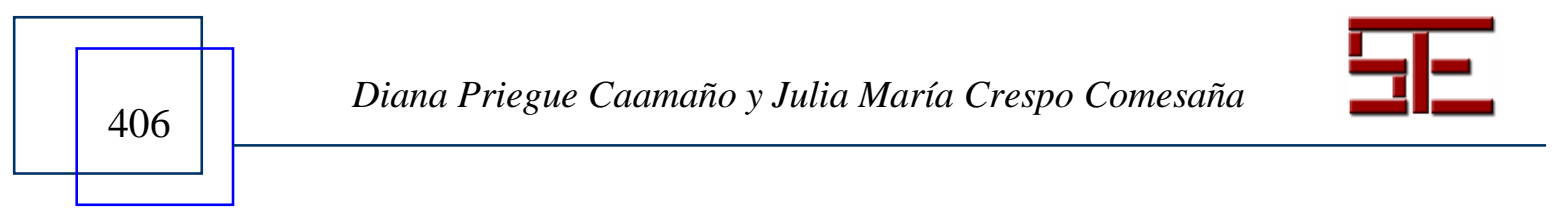




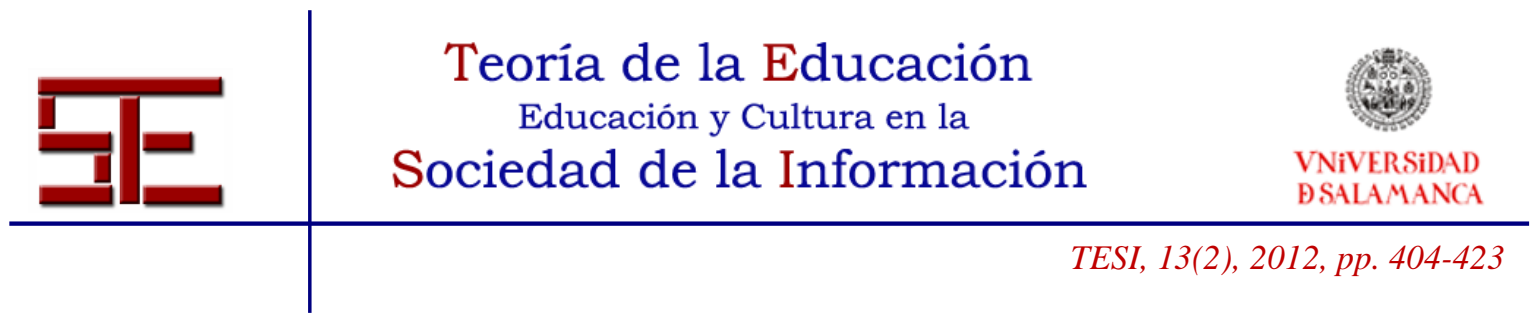

En este contexto de transformaciones a gran escala tampoco podemos pasar por alto la incidencia de otro de los fenómenos que más importancia ha cobrado en las últimas décadas. Nos referimos al incremento de la movilidad a nivel mundial y a la resultante emergencia de nuevos espacios multiculturales que demandan un mayor compromiso por parte de la escuela en la formación en los principios de la interculturalidad. Ciertamente, aunque la diversidad es un hecho intrínseco a las sociedades humanas, el continuo advenimiento de población inmigrante ha ido otorgando una mayor visibilidad social a las diferencias y ha acrecentado la necesidad de introducir nuevos enfoques con mayor repercusión práctica que permitan gestionar de manera eficaz las aulas con apreciable heterogeneidad étnica.

Sin lugar a dudas, estamos inmersos en un proceso de gran complejidad que requiere una profunda revisión de los planteamientos que hasta el momento han liderado los procesos educativos. Para ello uno de los primeros pasos debe ser explorar en mayor medida el potencial educativo de la tecnología, es decir, una vez constatadas sus posibilidades desde un punto de vista instrumental, conviene ahora profundizar en el aprovechamiento de las múltiples ventajas que nos ofrecen y, desde ellas, avanzar en el diseño de estrategias que favorezcan la asunción de las nuevas demandas que la sociedad ha encomendado a la escuela.

\section{TECNOLOGÍA Y NUEVAS NECESIDADES EDUCATIVAS: DE LOS CONOCIMIENTOS A LAS COMPETENCIAS}

La incorporación de las Tecnologías de la Información y la Comunicación (TIC) a los procesos de enseñanza-aprendizaje constituye uno de los mayores desafíos que debe afrontar nuestro sistema educativo. Este desafío es parte de un proceso de mayor calado con repercusiones que afectan a las distintas dimensiones de nuestra sociedad. Y es que, de un tiempo a esta parte, hemos sido testigos de numerosos avances tecnológicos que afectan tanto a aquellos ámbitos que compartimos como ciudadanos como a muchos otros que nos incumben como individuos particulares.

En este contexto no nos debe sorprender la proliferación de distintos posicionamientos sobre el papel que tiene que desempeñar la tecnología en la sociedad de la información. Los planteamientos han sido variados, y aun contrapuestos, pero moviéndose entre dos extremos que van desde los discursos apocalípticos que insisten en el fin de los ideales y valores de modelo humanista de la cultura, hasta aquellos que hacen apología de los medios tecnológicos como la

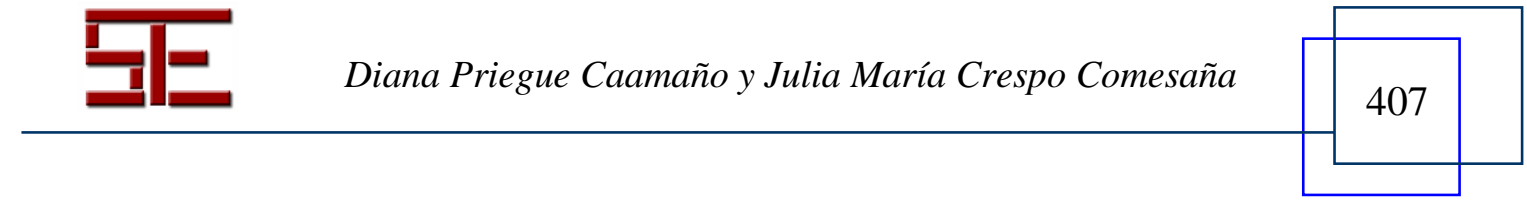




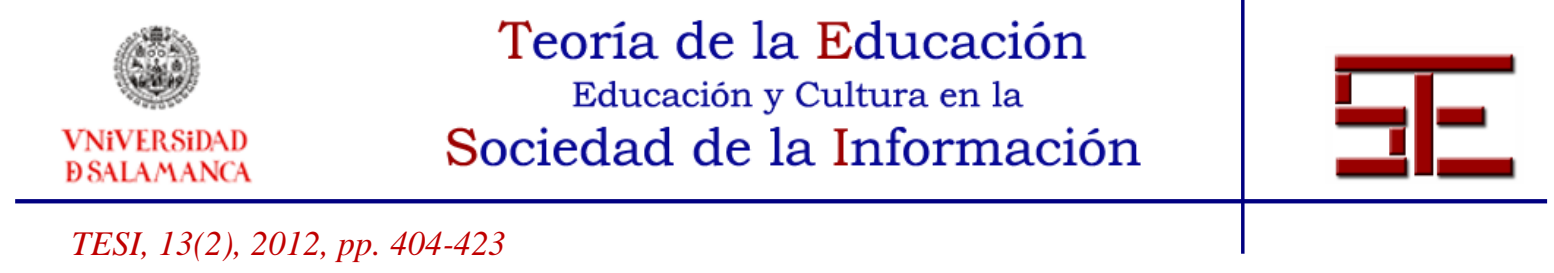

panacea de una sociedad más eficaz y llena de bienestar para sus ciudadanos (Area, 2009).

Como no podía ser de otra forma, las instituciones educativas también se han visto afectadas por las controversias derivadas de tan intensos debates. Esto se ha traducido en la difusión de varios enfoques (ver Mominó, Sigalés y Meneses, 2007), contrarios en determinados aspectos y complementarios en algunos otros, centrados en el estudio de la integración de las TIC en la educación.

En todo caso, en lo que sí hemos alcanzado un cierto consenso es en el reconocimiento de la influencia que ejercen los dispositivos tecnológicos en la vida de todos los ciudadanos pero, sobre todo, en la necesidad de asumir los desafíos educativos derivados de tal influencia.

Es claro que la sociedad red, tal y como la ha denominado Castells (1999), exige a las instituciones educativas un mayor compromiso en el desarrollo de un número creciente de habilidades, capacidades y actitudes. De acuerdo con Coll et al. (2007), la escuela debe revisar el viejo concepto de alfabetización y avanzar en la identificación de nuevas formas de alfabetización que faciliten el desarrollo de las competencias que demanda la sociedad actual. Sin lugar a dudas, disponer de las destrezas que implica el manejo de los medios tecnológicos, la capacidad para interactuar con personas de orígenes diversos, aprender a aprender, etc., son aspectos que hasta el momento han ocupado un segundo plano en los procesos de aprendizaje de nuestros estudiantes, pero que hoy en día se han convertido en elementos imprescindibles en la formación de la ciudadanía del siglo XXI.

No es extraño, por tanto, que el concepto Lifelong Learning haya adquirido la consideración de pieza clave para el desarrollo económico y social de la Unión Europea. Si la formación de una persona no puede reducirse a una determinada etapa educativa, una de las prioridades de las instituciones educativas debe ser favorecer el desarrollo de las competencias necesarias para aprender de manera autónoma. Haciendo nuestras las palabras de De Miguel $(2005,17)$ : el nuevo orden social "exige a cada sujeto una capacitación personal crítica que favorezca la interpretación de la información circulante y la generación del conocimiento propio que le permita aprender de forma continua".

No podemos seguir sin detenernos en otro término de gran relevancia en la sociedad actual y que ha significado el inicio de una profunda transformación en las instituciones educativas de nuestro tiempo. Nos referimos al concepto de competencia que, como es bien sabido, a pesar de tener su origen en un contexto

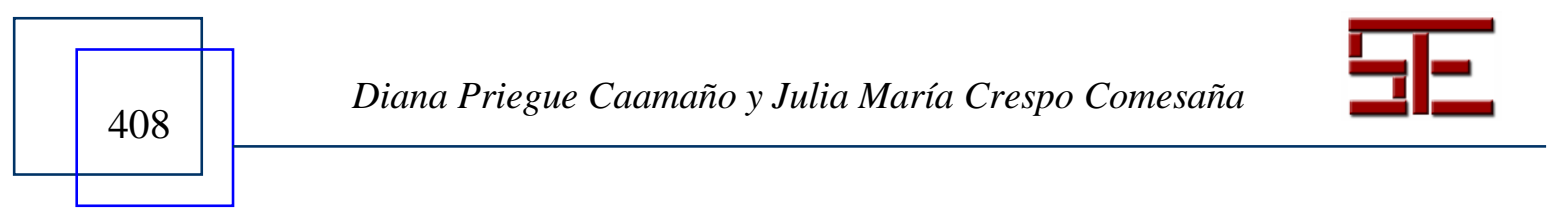




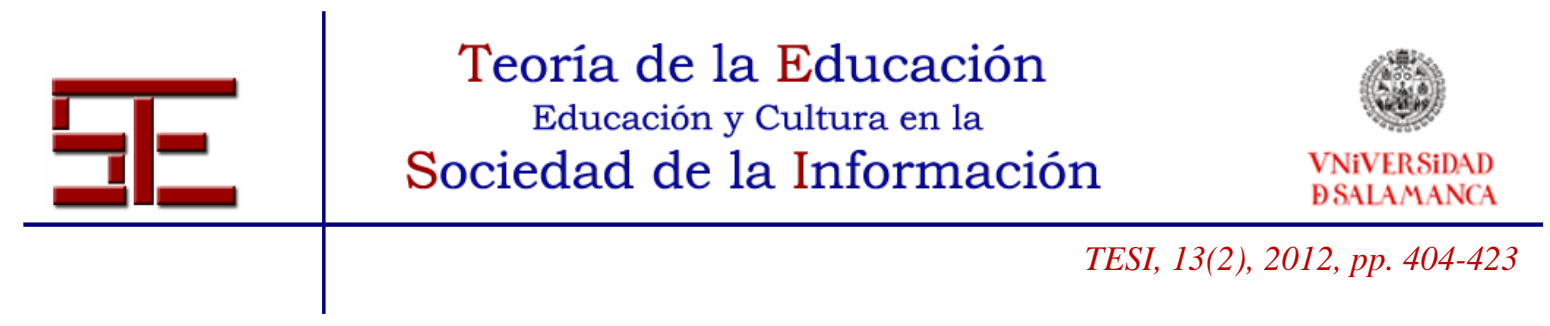

vinculado al empleo, en un periodo relativamente corto de tiempo, su alcance se ha dejado sentir con fuerza en las distintas reformas que se han llevado a cabo en los sistemas educativos de los países europeos. Concretamente, el proceso de reflexión en torno a las competencias en la educación básica, iniciado con el Informe DeSeCO (OCDE, 2005), culmina con la definición de un marco conceptual que pretende contribuir a la identificación de las denominadas competencias clave, es decir, el conjunto de conocimientos, destrezas y actitudes que han adquirido la condición de imprescindibles en la sociedad contemporánea. La propuesta de la OCDE considera tres bloques de competencias clave (ver Figura 1), estrechamente vinculadas con varios términos que, como veremos, son fundamentales en nuestra propuesta:

\section{Figura 1: Bloques de competencias clave}

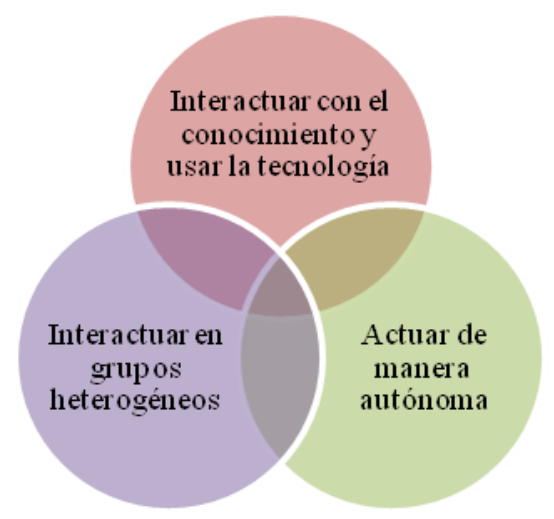

Fuente: Elaboración propia a partir de la propuesta de la OCDE (2005)

Como no podía ser de otra forma, también en España se han producido cambios importantes en la normativa sobre educación, situándose entre los más relevantes las modificaciones introducidas en los currículos de los distintos niveles de enseñanza, tanto obligatorios como postobligatorios, con la aprobación de la Ley Orgánica 2/2006, de 3 de mayo, de Educación (LOE) (BOE 04/05/20011).

En clara consonancia con lo establecido en las directrices y recomendaciones internacionales, tanto en la LOE como en la normativa que la desarrolla, la educación se concibe como un aprendizaje permanente que debe desarrollarse a lo largo de la vida. Consecuentemente, nuestro sistema educativo debe garantizar a la ciudadanía la posibilidad de adquirir y ampliar los conocimientos, capacidades, actitudes y

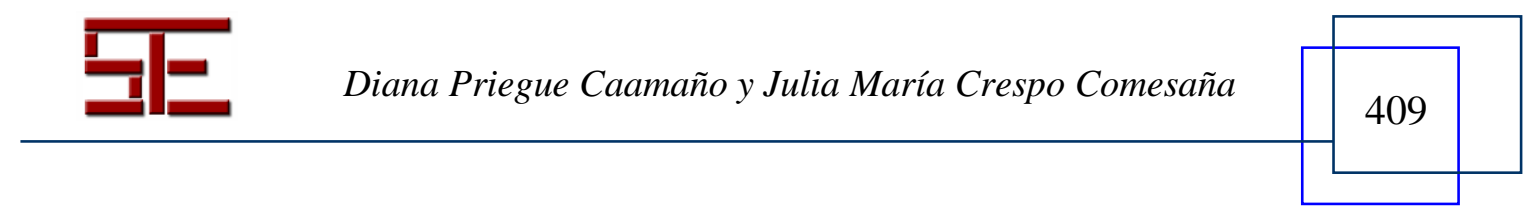




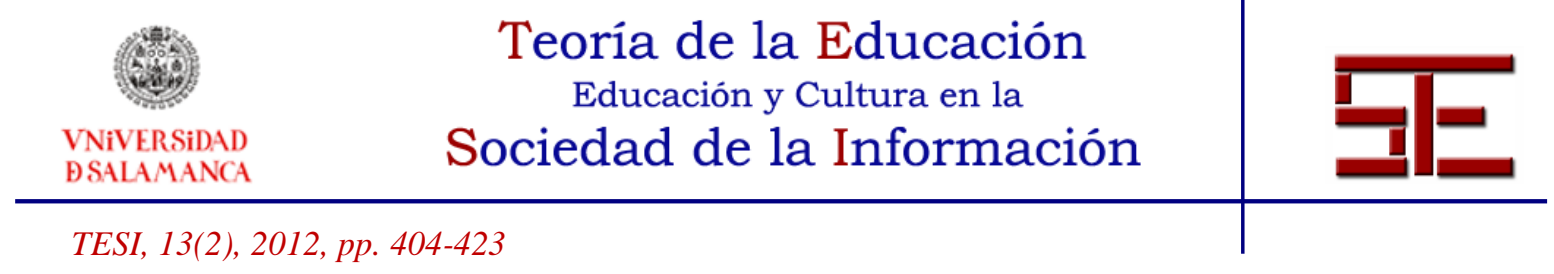

competencias necesarias para desarrollarse personal y profesionalmente tanto dentro como fuera de los contextos formales de aprendizaje.

La incorporación de las competencias básicas en los currículos de los niveles que componen la educación básica (educación primaria y educación secundaria obligatoria) responde a la necesidad de poner el acento en aquellos aprendizajes que se consideran imprescindibles para que los jóvenes puedan aprender a lo largo de su vida, realizarse personalmente, ejercer la ciudadanía activa, e incorporarse a la vida adulta de manera satisfactoria. Concretamente, y siempre tomando como referencia la propuesta realizada por la Unión Europea, se han identificado ocho competencias básicas: competencia en comunicación lingüística, competencia matemática, competencia en el conocimiento y la interacción con el mundo físico, tratamiento de la información y competencia digital, competencia social y ciudadana, competencia cultural y artística, competencia para aprender a aprender, y autonomía e iniciativa personal.

Tal y como se refiere en la citada ley, aunque las enseñanzas mínimas del currículo de la educación obligatoria son, a priori, suficiente garantía para que el alumnado alcance las competencias básicas, es preciso que tanto los distintos elementos que intervienen en el proceso de enseñanza-aprendizaje como la organización y funcionamiento de los centros promuevan su desarrollo.

Aunque este es un objetivo que incumbe prioritariamente a las etapas que componen la educación básica, la relevancia de esta cuestión también requiere que los niveles postobligatorios contribuyan al perfeccionamiento y consolidación de las competencias básicas. A modo de ejemplo podríamos referirnos al Bachillerato. Tal y como se recoge en el Real Decreto 1467/2007, de 2 de noviembre, por el que se establece la estructura del bachillerato y se fijan sus enseñanzas mínimas (BOE 6/11/2007), entre los objetivos de las materias comunes de la etapa se encuentra profundizar en aquellas competencias que tienen un carácter más transversal y favorecen que los estudiantes continúen aprendiendo. De otra parte, las materias de modalidad deben promover el desarrollo de aquellas competencias que, además de estar más vinculadas con un determinado ámbito de conocimiento, preparan al alumnado para la realización de estudios posteriores y/o favorecen la inserción en un determinado campo laboral.

Si bien no profundizaremos en ello, también en la enseñanza universitaria hemos presenciado intensas reformas con la construcción del Espacio Europeo de Educación Superior (EEES) a partir de la Declaración de Bolonia que, entre otros aspectos, han motivado la incorporación de las competencias a los planes de estudio de las distintas titulaciones. En total acuerdo con Bolívar (2008), aunque la introducción de las competencias en los niveles previos a la universidad tiene un origen y finalidades

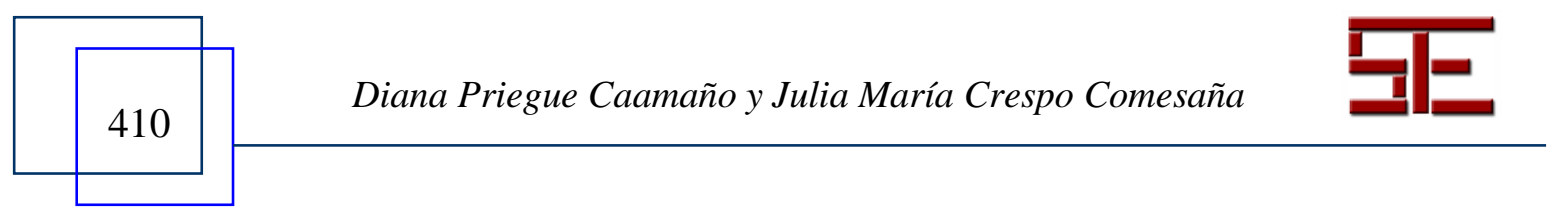




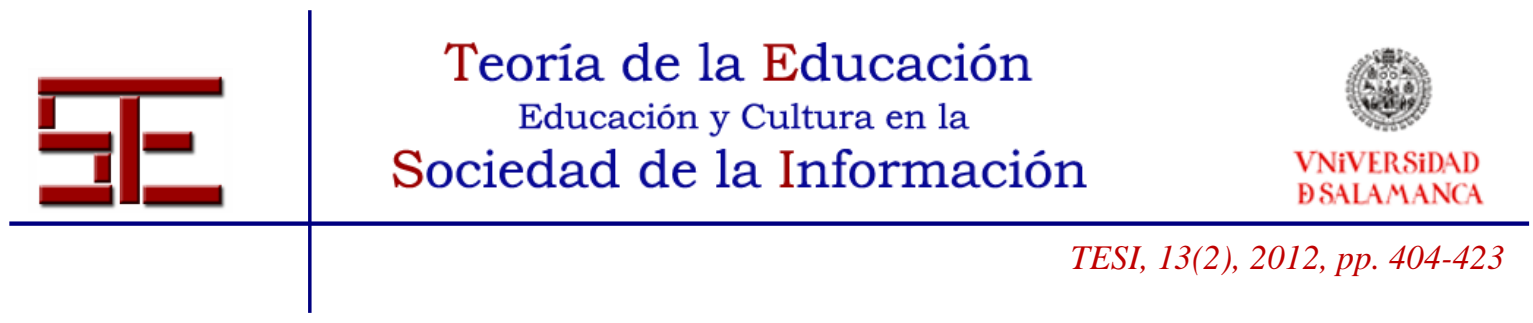

distintas, ambos planteamientos coinciden en considerar que los conocimientos adquiridos tienen escasas posibilidades de transferencia fuera de los contextos formales de aprendizaje y, además, están lejos de resolver las demandas que la sociedad actual plantea a la ciudadanía.

Aunque resulta difícil establecer prioridades, y más aún cuando hablamos de educación, creemos que uno de los elementos que necesita ser profundamente revisado tiene que ver con los aspectos metodológicos. Tal y como insiste Vinagre (2010), la adquisición de las competencias que necesita el alumno exige poner el acento en los procesos de aprendizaje y no, como viene siendo habitual, en los procesos de enseñanza. En definitiva, de lo que se trata es de avanzar en la construcción de entornos que permitan a los estudiantes ser los auténticos promotores del proceso de aprendizaje, al tiempo que incrementan las posibilidades de interacción tanto con los iguales como con los propios docentes. No olvidemos que el conocimiento no es resultado de un proceso individual, es decir, no puede entenderse al margen del contexto en el que surge, sino dentro de un espacio social con el que el individuo interacciona.

Y es este aspecto donde las TIC nos abren nuevas posibilidades de acción educativa a la vez que plantean nuevos desafíos, como por ejemplo el desarrollo de las competencias que implica el acceso y el uso responsable de los soportes digitales o la mejor capacitación de los docentes para gestionar éste y otros nuevos retos.

\section{AUTONOMÍA Y RESPONSABILIDAD DEL ALUMNADO: EL POTENCIAL EDUCATIVO DE LA WEB 2.0}

El estudio de las ventajas derivadas de la integración de las TIC en la enseñanza es un tema que ha tenido una intensa divulgación en los últimos años. Han sido muchos los expertos que han insistido en los efectos positivos derivados de las novedades que introducen las TIC en el proceso de enseñanza-aprendizaje. Por ejemplo, Gimeno (2001) hace referencia a las siguientes:

- Integran la palabra hablada y la escrita con sonidos e imágenes generando nuevas formas de trasformar los códigos de comunicación dominantes hasta ahora en los procesos educativos.

- Generan nuevas expectativas y posibilidades de integración de experiencias de aprendizaje.

- Facilitan la configuración de comunidades culturales más amplias.

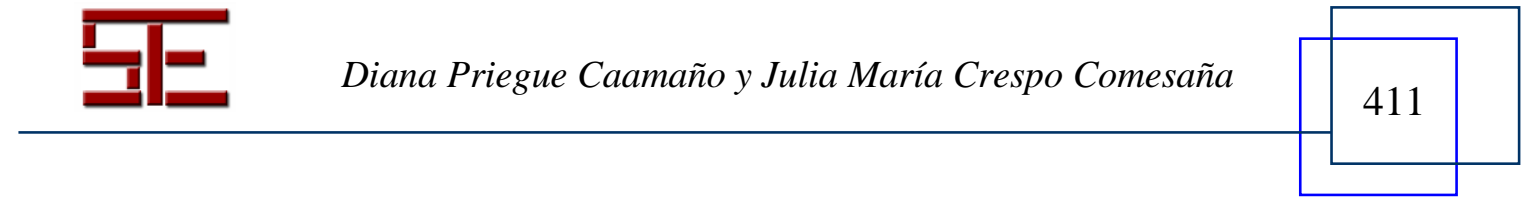




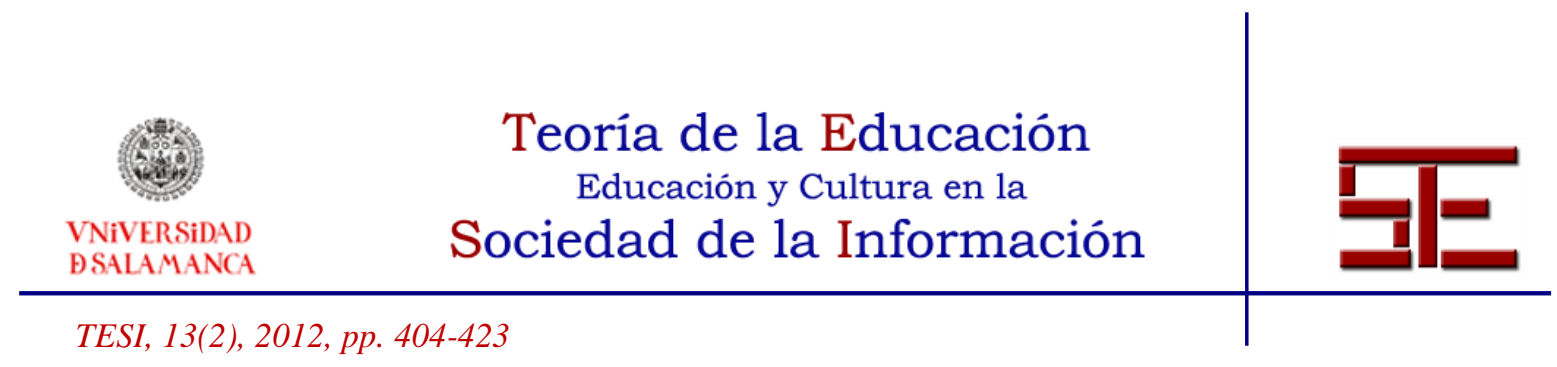

- Reordenan el espacio y el tiempo de cada sujeto abriendo nuevas posibilidades de elegir.

Otro de los puntos fuertes de las TIC se relaciona con las mayores opciones que ofrecen para diversificar el proceso de enseñanza-aprendizaje y de atender, en mayor medida, a las necesidades particulares que pueda presentar el alumnado. Además, tal y como hemos puesto de manifiesto en más ocasiones (ver Priegue, 2009), el aprovechamiento de sus ventajas permite introducir importantes mejoras en aulas donde existe una apreciable heterogeneidad étnica y cultural.

Como veremos a continuación, el potencial de estos soportes para la atención a la diversidad del alumnado está estrechamente relacionado con algunas de sus características. En concreto, los estudios realizados en torno a las propiedades de los dispositivos tecnológicos (ver Badia y Monereo, 2005) apuntan a seis aspectos que recogemos en el siguiente cuadro y que acompañamos de los posibles efectos positivos en el nivel de autonomía y responsabilidad de los estudiantes en el proceso de enseñanza-aprendizaje:

Cuadro 1. Características de las TIC y desarrollo de la autonomía y responsabilidad del alumnado en el proceso de enseñanza-aprendizaje CARACTERÍSTICAS DE LAS TIC DESARROLLO DE LA

AUTONOMÍA Y RESPONSABILIDAD

\begin{tabular}{|c|c|c|}
\hline Formalismo & $\begin{array}{l}\text { Para que la interacción con los } \\
\text { dispositivos funcionen es } \\
\text { necesario seguir secuencias de } \\
\text { procedimientos bien definidas. }\end{array}$ & $\begin{array}{l}\text { Exige planificar y analizar las acciones que hay } \\
\text { que realizar con la tecnología para después } \\
\text { llevarlas a cabo de manera autónoma. }\end{array}$ \\
\hline Interactividad & $\begin{array}{l}\text { Alta interacción entre las acciones } \\
\text { del usuario y la información. }\end{array}$ & $\begin{array}{l}\text { Promueve la adquisición de destrezas en la } \\
\text { búsqueda y selección de la información. } \\
\text { Requiere una mayor responsabilidad en la toma } \\
\text { de decisiones a lo largo del proceso y, a su vez, } \\
\text { un grado de implicación más elevado. }\end{array}$ \\
\hline Dinamismo & $\begin{array}{l}\text { Capacidad de } \text { transmitir } \\
\text { información dinámica. }\end{array}$ & $\begin{array}{l}\text { Favorece el trabajo con simulaciones reales y el } \\
\text { desarrollo de estrategias de resolución de } \\
\text { problemas que pueden ser aplicadas en } \\
\text { situaciones virtuales. }\end{array}$ \\
\hline Multimedia & $\begin{array}{l}\text { Combinación de sistemas } \\
\text { semióticos para representar la } \\
\text { información (escritura, sonido, } \\
\text { imágenes...). }\end{array}$ & $\begin{array}{l}\text { Exige procesos de reflexión complejos sobre los } \\
\text { lenguajes utilizados en los medios digitales y la } \\
\text { realidad que transmiten. } \\
\text { Favorece el desarrollo de una actitud crítica ante } \\
\text { los medios. }\end{array}$ \\
\hline Hipermedia & $\begin{array}{l}\text { Presentación simultánea y radial } \\
\text { de la información (no lineal ni }\end{array}$ & $\begin{array}{l}\text { Requiere el establecimiento de relaciones } \\
\text { múltiples. }\end{array}$ \\
\hline
\end{tabular}

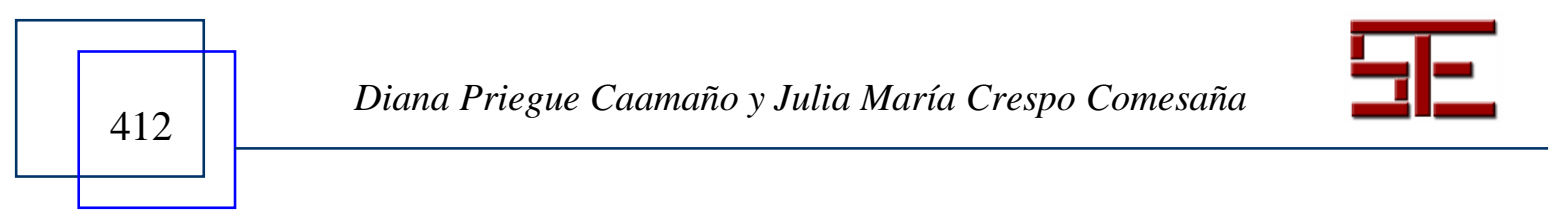




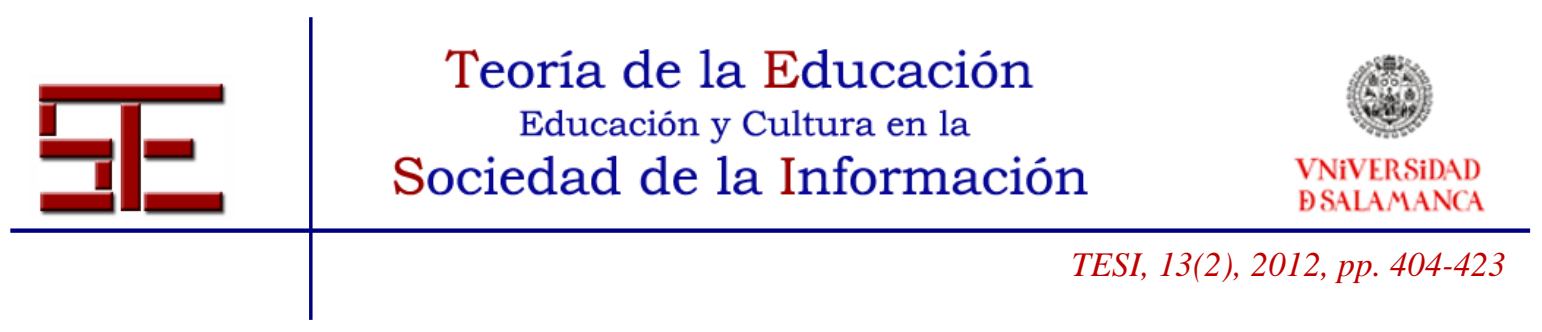

\begin{tabular}{lll}
\hline & secuencial). & $\begin{array}{l}\text { Promueve la indagación y la experimentación de } \\
\text { manera autónoma. }\end{array}$ \\
Conectividad & $\begin{array}{l}\text { Mayores posibilidades para el } \\
\text { trabajo en red. }\end{array}$ & $\begin{array}{l}\text { Permite el trabajo cooperativo a través de la } \\
\text { Red. } \\
\text { Facilita el desarrollo de competencias cívico- } \\
\text { sociales e interculturales. }\end{array}$ \\
\hline
\end{tabular}

Fuente: Elaboración propia.

Teniendo en cuenta los objetivos de este trabajo, nos interesa de manera particular el último de los aspectos que venimos de referir. Como es bien sabido, el interés por el estudio de los medios digitales en el ámbito escolar no es un asunto reciente y por ello contamos con numerosas investigaciones que destacan las múltiples opciones que nos ofrece la tecnología para mejorar los procesos educativos. Sin embargo, desde nuestro punto de vista, lo que realmente puede suponer un importante salto cualitativo es la posibilidad de utilizar el espacio digital de comunicación (ciberespacio) como un nuevo escenario de aprendizaje. En otras palabras, la significación de las TIC no debe reducirse a una perspectiva meramente instrumental, sino que lo realmente relevante son las mayores posibilidades que ofrecen para albergar entornos de interacción y colaboración más amplios que tendrán ingentes posibilidades de utilización en el ámbito de la formación. Es evidente que las TIC en un contexto educativo perderían parte de sus posibilidades si únicamente se plantean como un medio de apoyo al libro de texto y dentro de una concepción curricular orientada básicamente a la transmisión de conocimientos.

Sin lugar a dudas, que Internet haya pasado de ser un espacio de lectura a convertirse en un espacio de lectura-escritura ha sido el motor de una nueva revolución tecnológica: el auge de la web 2.0. Este nuevo espacio de interrelación humana es lo que Echeverría (2000) denomina "tercer entorno" que, a diferencia del entorno natural y del urbano, es decir, de aquellos en los que tradicionalmente ha actuado el ser humano, incrementa de manera notable las posibilidades de interacción por sostenerse al margen de los límites establecidos por las dimensiones espacio-tiempo.

Nos parece muy interesante la propuesta de Tubela y Vilaseca (2005) al referirse a dos modelos de ciberespacio desde el punto de vista de su aprovechamiento. De una parte, el modelo de ciberespacio de consumo, cuyo objetivo se limita al acceso a bienes y servicios y donde las relaciones interpersonales son casi inexistentes. De otra parte, el modelo de ciberespacio de comunidad, cuyo eje central es la comunicación entre usuarios y el aprovechamiento de las estructuras tecnológicas por encima de los parámetros para los que han sido diseñadas inicialmente. Al respecto, Revuelta y Pérez $(2009,36)$ afirman que este tipo de uso de las estructuras favorece la "racionalización

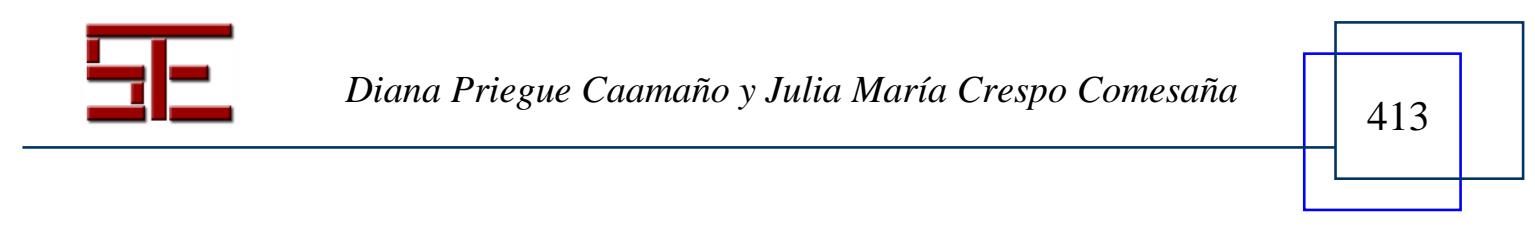




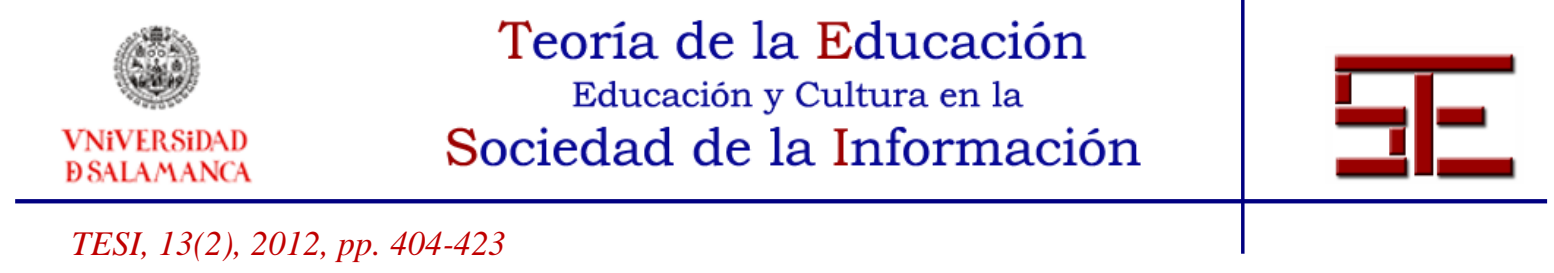

democrática del ciberespacio", esto es, la apropiación por parte de los usuarios de los nuevos entornos tecnológicos, redefiniendo sus funciones para nuevas finalidades y, a su vez, permitiendo el diseño de redes susceptibles de generar una relación comunitaria verdaderamente autónoma, es decir, por encima de la racionalidad funcional de la tecnología.

Así pues, las comunidades virtuales de aprendizaje son aquellas que tienen como foco un determinado contenido o tarea de aprendizaje, y se caracterizan porque, además de constituirse como una comunidad de intereses o de participación, utilizan los soportes digitales como infraestructura para consolidar y ampliar las redes de comunicación y de intercambio, al tiempo que como instrumento para promover el aprendizaje de sus miembros (Coll, Bustos y Engel, 2007) y, sobre todo, con elevadas posibilidades para incrementar el grado de autonomía y responsabilidad del alumnado en su proceso formativo.

Seguidamente se recogen las etapas que, a nuestro parecer, conformarían la creación de una comunidad virtual que pretende incidir de manera particular en el desarrollo de la autonomía y la responsabilidad de los estudiantes en el proceso de aprendizaje. Para ello hemos realizado una adaptación de la propuesta de Salmon (2000; cit. en Martín y Quiroz, 2006, 312):

- $1^{\text {a }}$ etapa: Acceso y motivación. El principal objetivo es reconocer la utilidad práctica y efectiva que una comunidad virtual de aprendizaje puede proporcionar al grupo en general y a cada individuo particularmente. Claro está que, previamente, es necesario contar con determinadas competencias tecnológicas, caso del manejo del hardware y software implicado en el acceso a las plataformas virtuales.

- $2^{a}$ etapa: Compromiso y socialización en línea. Se trata, principalmente, de establecer identidades virtuales y relaciones entre los participantes. La calidad de los vínculos establecidos determinará en gran medida el desarrollo de las etapas posteriores.

- $3^{\text {a }}$ etapa: Intercambio de información. La finalidad es conseguir compartir información relevante en función de las propias necesidades, las de los otros participantes y de la comunidad en su totalidad. Además, es importante que los implicados perciban los aspectos positivos derivados del proceso.

- $4^{\mathrm{a}}$ etapa: Construcción del conocimiento. Ésta es una de las fases clave pues el objetivo es lograr la construcción co-participativa de nuevos conocimientos a partir de las aportaciones de todos los participantes.

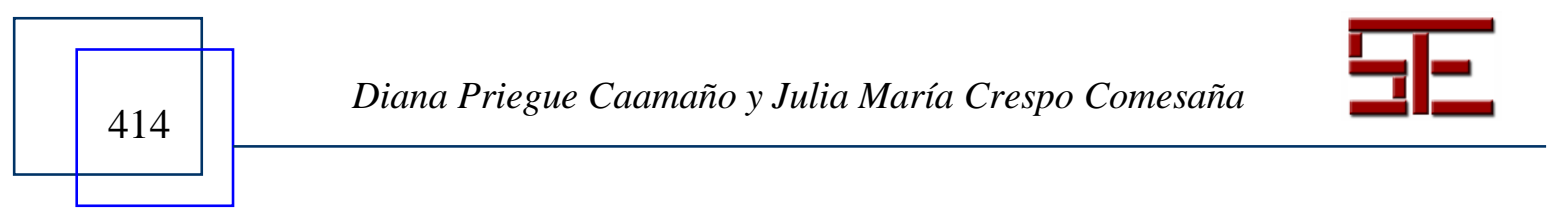




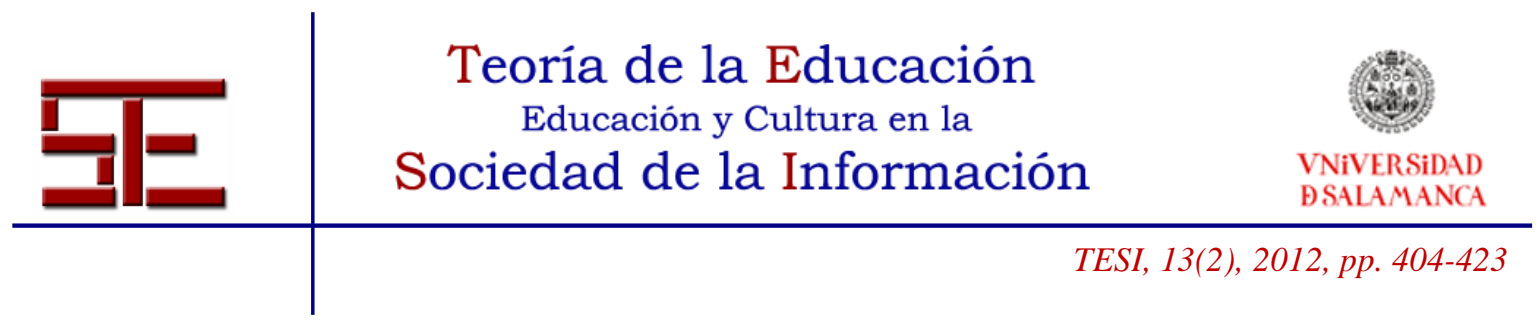

- $5^{a}$ etapa: Desarrollo. Se trata de usar el proceso para alcanzar metas personales, e integrar los conocimientos derivados de la implicación en la red con lo aprendido en otros contextos.

- $6^{\text {a }}$ etapa: Consolidación. El propósito de esta última etapa es que la red permanezca en el tiempo o sea el origen de nuevas redes con objetivos más amplios. Para que podamos hablar de consolidación, el nivel de implicación de los participantes debe mantenerse.

Resumidamente, las claves que favorecen el éxito de este tipo de comunidades pasan por compartir objetivos o intereses comunes, tener un sentimiento de pertenencia al grupo, y un compromiso activo de todos los miembros. A todo ello debemos añadir su gran potencial para la creación de estructuras de interacción cooperativa que, como se ha constatado en no pocos trabajos (ver Santos, Lorenzo y Priegue, 2009), constituye un planteamiento que promueve la responsabilidad y la autonomía del alumnado en el proceso de enseñanza-aprendizaje.

Antes de continuar nos gustaría hacer referencia a otro asunto que hasta el momento, al menos en nuestro país, ha sido menos explorado, si bien se encuentra directamente relacionado tanto con los nuevos espacios de interacción social de los estudiantes como con las responsabilidades educativas derivadas del orden social actual. Desde nuestro punto de vista, en ocasiones olvidamos que las ventajas que ofrecen los medios tecnológicos y el acceso a Internet, en y para el desarrollo social y personal de los jóvenes, son casi tantas como los riesgos que comporta su uso de forma irresponsable.

Ciertamente, en los últimos años se ha incrementado de manera considerable la preocupación por el estudio de los riesgos que presentan las TIC a la población más joven. A nivel internacional, distintos organismos públicos han apoyado la realización de varias investigaciones centradas en el análisis de las relaciones entre los jóvenes y determinados soportes tecnológicos. Concretamente, uno de los proyectos que ha tenido mayor difusión ha sido el EU Kids Online (ver Garmendia et al., 2011), enmarcado en programa "Safer Internet" de la Comisión Europea, y teniendo por principal objetivo mejorar el conocimiento sobre las prácticas y experiencias de los menores europeos con respeto al riesgo y seguridad en el uso de Internet y las TIC. La finalidad última es contribuir a la promoción de un entorno digital más seguro para la población más joven. Para ello se han realizado entrevistas a menores con edades comprendidas entre los $9 \mathrm{y}$ los 16 años, así como a sus padres, en un total de 25 países europeos, entre ellos España. La muestra utilizada asciende a un total de 25.420 niños y niñas, todos ellos usuarios de Internet. Las cifras para nuestro país indican que el $84 \%$ de los menores españoles utilizan Internet en el hogar y la mitad de ellos (42\%) afirman acceder a la red de redes

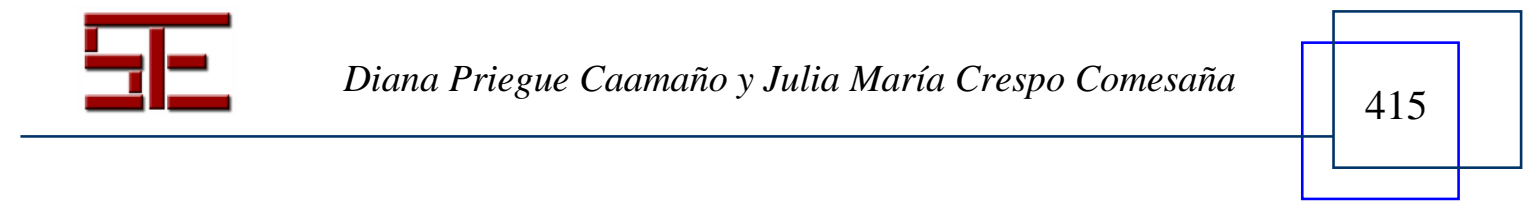




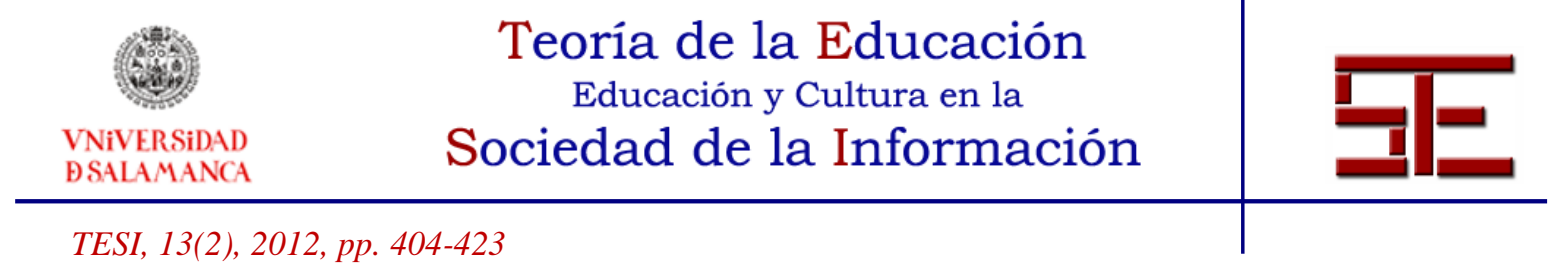

en su propio dormitorio, es decir, en un espacio donde la supervisión de los progenitores suele ser menor. A pesar de que estamos hablando de una proporción importante, es bastante inferior a la media europea (54\%) y se aleja bastante de la registrada en otros países del viejo continente, caso de Dinamarca donde alcanza el 74\%.

Además, los menores que han participado en el estudio manifiestan que el principal motivo para utilizar Internet es la realización de las tareas escolares (83\%). A corta distancia y ocupando el segundo y tercer puesto se sitúan las actividades de ocio y/o entretenimiento y la comunicación con otras personas. También debemos resaltar que después del hogar, la escuela es el lugar en el que los menores usan en mayor medida Internet $(63 \%)$.

En base a los datos derivados de este estudio, y aun sabiendo que la importancia que tiene este asunto exige la puesta en práctica de acciones de mayor envergadura que impliquen a otros agentes educativos, caso de la familia, creemos que un buen punto de partida lo podemos situar en las actividades que los menores realizan con las TIC. Así pues, si sabemos que las tareas escolares, el entretenimiento y la interacción con los iguales son las principales razones para utilizar los medios digitales, hemos de suponer que las estrategias educativas que integren estos tres aspectos serán especialmente adecuadas para motivar al alumnado y alcanzar un nivel de participación más elevado, al tiempo que, como veremos a continuación, se favorece el desarrollo de otro tipo de competencias.

\section{EL DESARROLLO DE COMPETENCIAS INTERCULTURALES A TRAVÉS DE LA COOPERACIÓN EN LA RED}

Disponemos de numerosas evidencias empíricas que han constatado como el trabajo entre pares o expertos, es decir, la interacción en los procesos de enseñanza-aprendizaje, incrementan las posibilidades de éxito (Rogoff, 1993). En no pocas ocasiones a este tipo de trabajo se le ha llamado cooperativo o colaborativo, llegando a utilizarse ambos términos en la literatura científica como sinónimos, pero también como antónimos. Pues bien, aunque no nos detendremos en explicar las diferencias entre ambos métodos (ver Barkley, Cross y Mayor, 2007), antes de seguir, queremos dejar claro que nuestra propuesta se fundamenta en estructuras de interacción cooperativa, por ser este un planteamiento especialmente apropiado tanto para el desarrollo de la reflexión y la autonomía del alumnado en el proceso de enseñanza-aprendizaje y también, como para el desarrollo de competencia de corte intercultural.

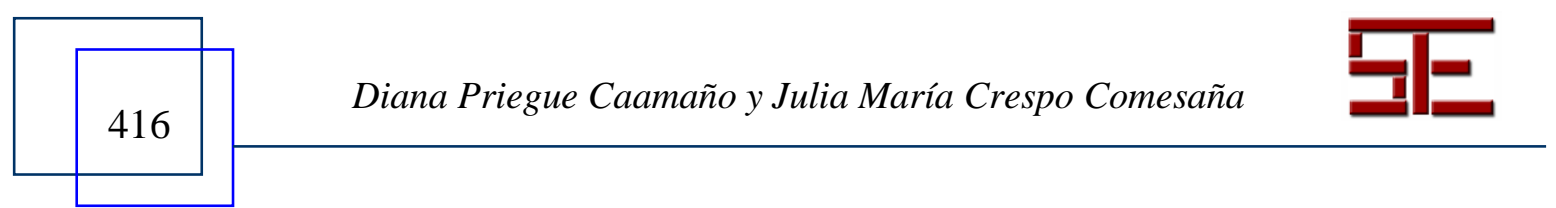




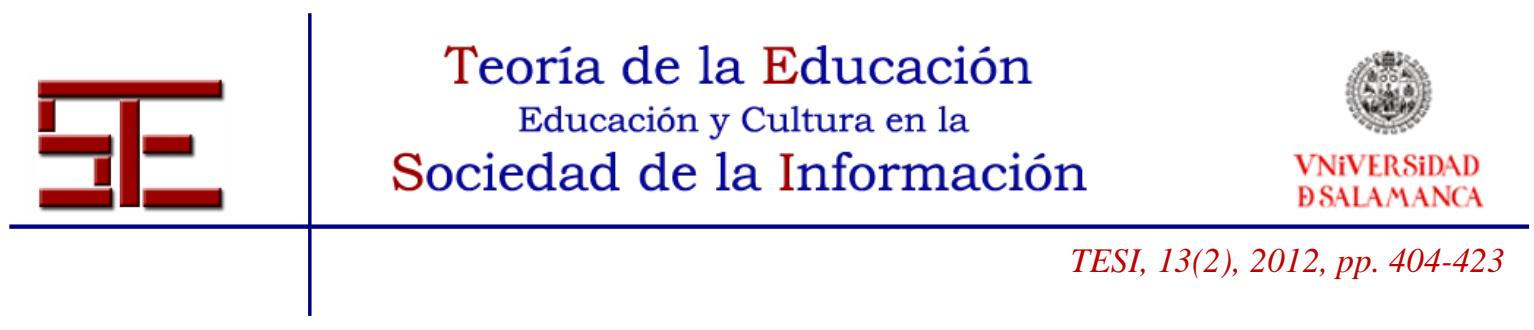

Naturalmente, de las potenciales virtualidades que presentan las técnicas de aprendizaje cooperativo nos interesa especialmente la mejora que parecen producir en el esfuerzo por el aprendizaje entre compañeros, porque aumentan la motivación general, la implicación en las tareas y la ayuda que se proporcionan entre sí, amén de que propicia la reducción de prejuicios étnicos. Las investigaciones realizadas sobre el aprendizaje cooperativo en equipos heterogéneos apoyan dicha teoría, así como la eficacia de la cooperación para favorecer la tolerancia y la integración de todos los alumnos en contextos interétnicos (Slavin, 1999; Díaz- Aguado, 2003).

Los espacios en los que se coopera, sea presencial o virtualmente, crean comunidades de ayuda en el estudio y en la indagación, en las cuales los alumnos se ven a sí mismos con responsabilidades específicas en los planos individual y grupal, independientemente de etnia, edad, clase o género. Repárese en la excelente oportunidad formativa que ofrecen aquellas situaciones escolares que, por su composición heterogénea, permiten un fructífero conocimiento de las distintas señas de identidad que caracterizan a los miembros de la comunidad educativa.

El aprendizaje apoyado en la comunicación por ordenador, conocido con las siglas CSCL (Computer Supported Collaborative Learning), representa el encuentro entre la difusión de las TIC en los entornos de aprendizaje y las técnicas de aprendizaje cooperativo. En otras palabras, la aplicación de los conceptos que definen el aprendizaje cooperativo usando como infraestructura de comunicación los recursos tecnológicos, y especialmente los groupware como una nueva categoría de software desarrollada sobre una red de telecomunicaciones que favorece el trabajo cooperativo desde localizaciones y momentos diferentes, permite un contexto versátil de cooperación entre los participantes.

El potencial de estos soportes en el desarrollo de competencias de corte intercultural tiene que ver, fundamentalmente, con dos cuestiones. Por una parte, la naturaleza de su uso y funcionamiento favorece estructuras de participación democráticas y combina aprendizajes de tipo cognitivo, social y emocional. Y, por otra, porque la eliminación del espacio como distancia física entre los interlocutores no lleva aparejada la desaparición del entorno social que rodea a esos mismos interlocutores (Martínez y Prendes, 2003). Es evidente que los procesos de comunicación se establecen y se construyen desde los espacios de significación cultural de cada individuo, por lo cual la implicación en redes de este tipo es susceptible de favorecer el conocimiento de realidades y representaciones distintas a las propias.

A ello debemos añadir que todos los participantes aportan su actividad a fin de alcanzar una meta común, encontrándonos en este punto con una de las premisas básicas del

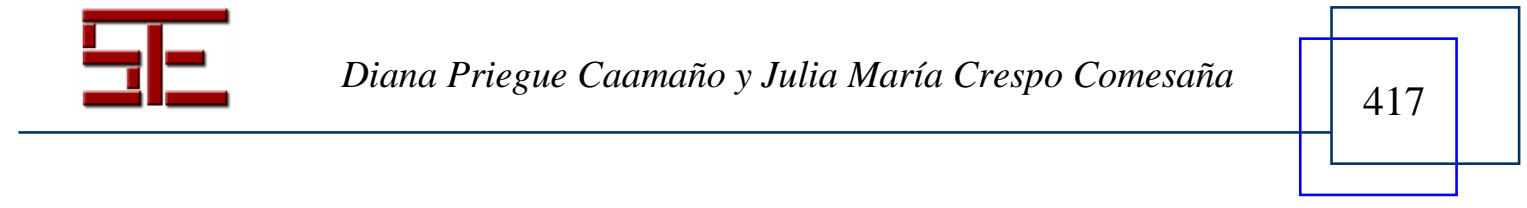




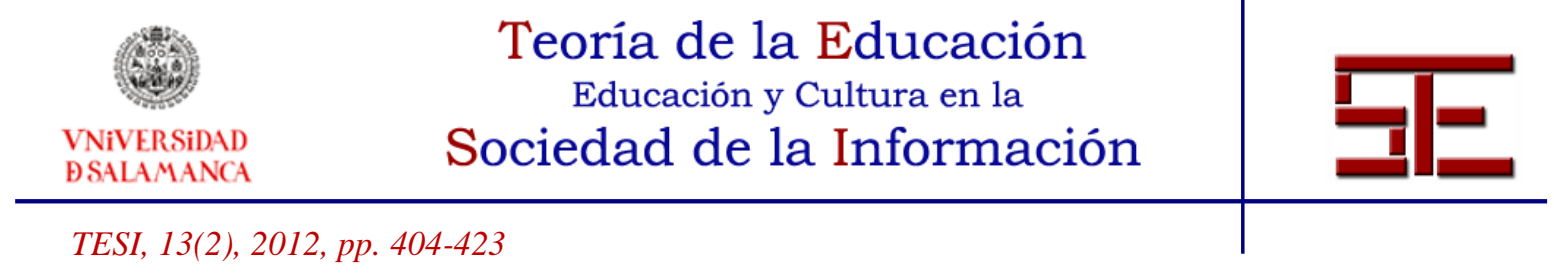

aprendizaje cooperativo, que se ha demostrado un procedimiento clave para adaptar la educación a los cambios sociales y al desarrollo de proyectos interculturales (ver DíazAguado, 2003; Santos y Lorenzo, 2005; Santos, Lorenzo y Priegue, 2009).

Veamos ahora con más detalle los aspectos que mejor despuntan la utilización del CSCL en el desarrollo de competencias interculturales:

En primer lugar, debemos hacer hincapié en la idoneidad de estas estructuras para la asunción de responsabilidades compartidas y el establecimiento de metas de equipo, por encima de comportamientos individualistas y de la competitividad, relegando a un segundo plano las diferencias que puedan existir entre los participantes y fortaleciendo el sentimiento de comunidad y necesidades compartidas. Así pues, una de las claves del éxito reside en crear interdependencia positiva entre los integrantes del grupo, es decir, la necesidad de que trabajen juntos para conseguir los objetivos establecidos en y para la comunidad.

Otro de sus aspectos positivos, también vinculado a lo anterior, tiene que ver con su contribución a la educación en y para la democracia. El diálogo, la confrontación de ideas y la participación son herramientas esenciales para el buen funcionamiento de estas estructuras y, al mismo tiempo, elementos fundamentales para el desarrollo de una sociedad democrática (Santos y Lorenzo, 2009).

En último lugar, la participación en estas redes favorece la aceptación y la valoración positiva de la diversidad, entendida ésta en un sentido amplio. No nos referimos únicamente a las diferencias que puedan existir por razones culturales, o de género, sino a la diversidad intrínseca que nos es propia como seres particulares. Además, tampoco podemos olvidar que una de las claves para el éxito de este tipo de estructuras de participación es la cohesión de la comunidad, lo cual implica la aceptación y el respeto a todos los miembros del grupo por encima de las diferencias que entre ellos puedan existir.

En este sentido, destacamos varios entornos virtuales cuyo funcionamiento se ajusta a nuestra propuesta. Además de plataformas más conocidas (sirva de ejemplo Moodle), disponemos de otros sistemas, caso del BSCW (Basic Support for Cooperative Working) que, como su propio nombre indica, constituye un entorno basado en el trabajo cooperativo que ofrece un amplio abanico de posibilidades para el docente, ya que combina la navegación y la información, y permite compartir documentos a través de distintas plataformas (Windows, Macintosh o Unix) sin necesidad de instalar ningún software adicional; únicamente es necesario un navegador de Internet ordinario (por ejemplo, el Internet Explorer). Asimismo, permite supervisar la creación, lectura o

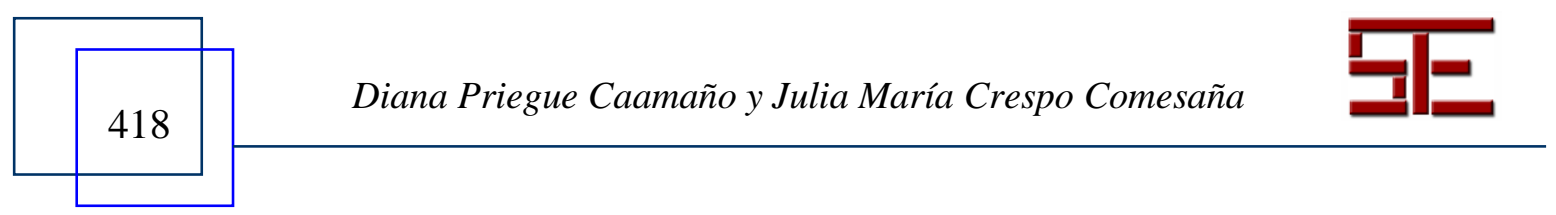




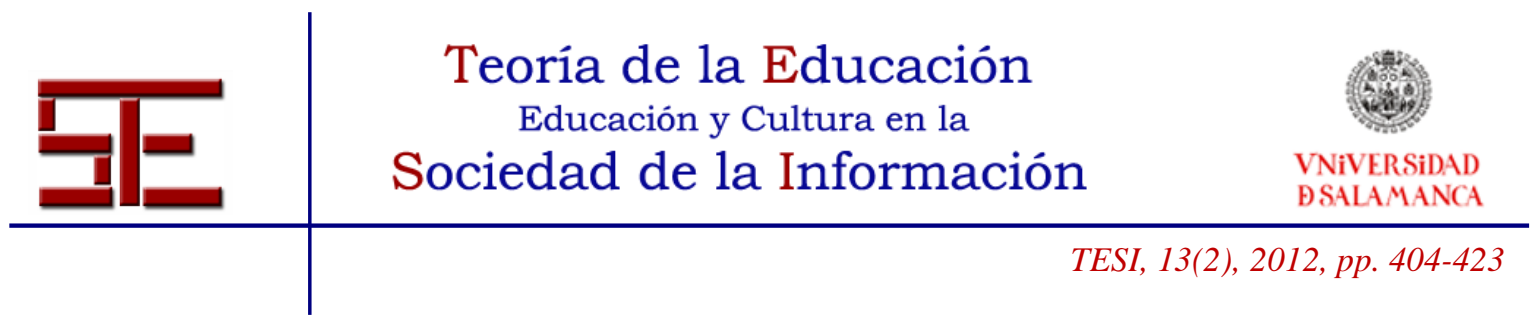

modificación de información a través de un sistema de alerta que nos informa de la actividad de otros usuarios del entorno.

Aunque en este trabajo tan sólo nos refiramos a una de ellas, en los últimos años se han desarrollado numerosas herramientas groupware bajo licencias de software libre de fácil acceso para todo tipo de organizaciones, con prestaciones muy similares a las que nos proporcionan distintas marcas comerciales, habitualmente menos accesibles por su elevado coste.

En la práctica, por más que todavía reste mucho por hacer, se han llevado a cabo algunas experiencias que han obtenido buenos resultados. Este es el caso de la iniciativa eTwinning, una acción que forma parte del programa eLearning de la Unión Europea que ofrece a los centros escolares la posibilidad de colaborar con centros de otros países europeos a través de las TIC. Concretamente, eTwinning (ver http://www.etwinning.net) promueve los "Hermanamientos Escolares" entre centros educativos de una treintena de países europeos a fin de construir puentes de comunicación y aprendizaje cooperativo gracias al uso de las TIC.

Otro ejemplo, tal vez menos conocido, lo encontramos en el proyecto Cultura (ver Vinagre, 2010), una iniciativa surgida en Francia y vinculada al aprendizaje de lenguas extranjeras. Concretamente, en el proyecto participan grupos de alumnos de dos países y culturas diferentes que, además de pertenecer a instituciones educativas de características similares, son estudiantes de la lengua que se habla en el país del otro grupo. Partiendo de que la comunicación intercultural es mucho más que el intercambio de información sobre las tradiciones o prácticas culturales, se hace hincapié en la necesidad de que exista un proceso dinámico de negociación de significados y comprensión de las diferentes perspectivas o miradas sobre el mundo. Con tal finalidad, se ha creado una plataforma digital con múltiples aplicaciones en la que los estudiantes de ambos grupos trabajan en el análisis y construcción de distintos materiales, participan en foros de debate, reflexionan sobre distintas cuestiones, etc.

Probablemente existan experiencias de corte similar a las que podríamos hacer referencia. Sin embargo, la escasa difusión de muchas de las iniciativas llevadas a cabo en los centros educativos limita sus posibilidades de desarrollo en otros contextos. Y aunque los dispositivos digitales podrían introducir importantes mejoras en la divulgación de experiencias exitosas, nos volvemos a encontrar con una clara infrautilización de su potencial para conectar a alumnos, centros y profesores, pero también para servir de soporte a un proyecto intercultural de naturaleza más global.

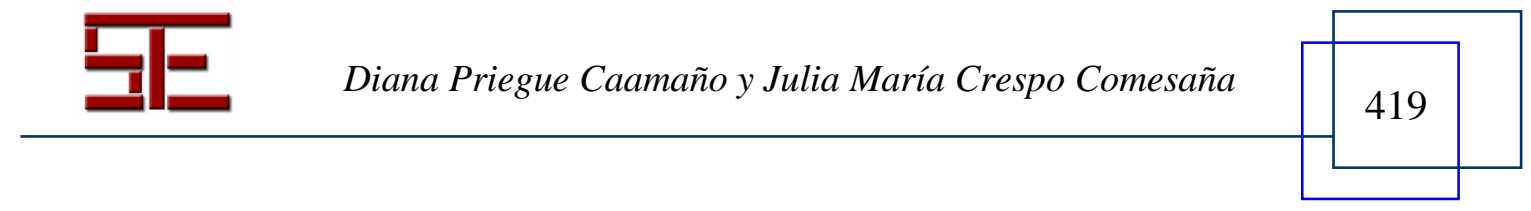




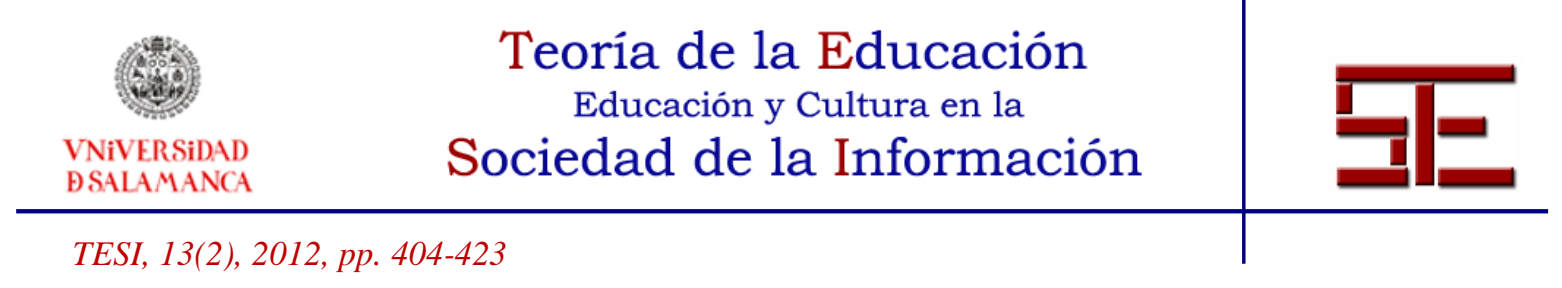

\section{CONSIDERACIONES FINALES}

Después del camino recorrido, creemos que pocas dudas podemos albergar sobre los beneficios que pueden derivarse de la incorporación de las TIC al proceso de enseñanza-aprendizaje. Aunque hasta el momento ha prevalecido una visión excesivamente instrumental sostenida en parámetros metodológicos tradicionales, los procesos educativos que demanda nuestra sociedad requieren la introducción de planteamientos más centrados en los estudiantes y orientados a la adquisición de las competencias que se consideran imprescindibles para la ciudadanía del siglo XXI. Y entre ellas, junto con la autonomía y la responsabilidad, mención especial merecen aquellas que facilitan el establecimiento de relaciones positivas con personas de orígenes diversos, sobre todo, teniendo en cuenta la mayor movilidad a escala global y la ampliación de los espacios de interacción interpersonal.

En este contexto, otra de las prioridades debe ser la mejor capacitación del profesorado para un mayor dominio de las herramientas tecnológicas. Este es un requisito imprescindible, tanto para aprovechar las ventajas que pueden introducir los soportes digitales en los procesos de enseñanza-aprendizaje, como para enfrentar las exigencias que plantea la sociedad del conocimiento al desarrollo personal y profesional de los docentes, entre las que también se sitúa la gestión educativa de la diversidad étnicocultural.

Aunque en este trabajo nos hayamos centrado en explorar el potencial pedagógico de las TIC, no podemos terminar sin referirnos a la necesidad de estudiar en mayor medida las consecuencias que, a largo plazo, puede tener el uso de las tecnologías digitales en los comportamientos, en las formas de relacionarse y en una socialización excesivamente sostenida en las interacciones con el grupo de iguales. No obstante, el interés de la investigación social y educativa por esta cuestión debe acompañarse de estrategias que promuevan un mayor compromiso entre familia-escuela en el uso seguro y responsable de las tecnologías digitales.

Tal y como sucede con tantos otros asuntos, el centro escolar se presenta como uno de los espacios más apropiados para gestionar una cuestión de gran trascendencia educativa y con evidentes repercusiones en un contexto social más amplio que, probablemente, en los próximos años será objeto de interés para expertos de distintas disciplinas.

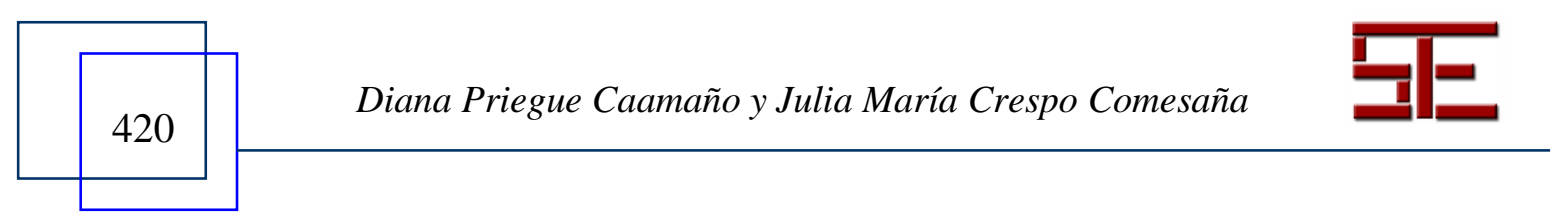




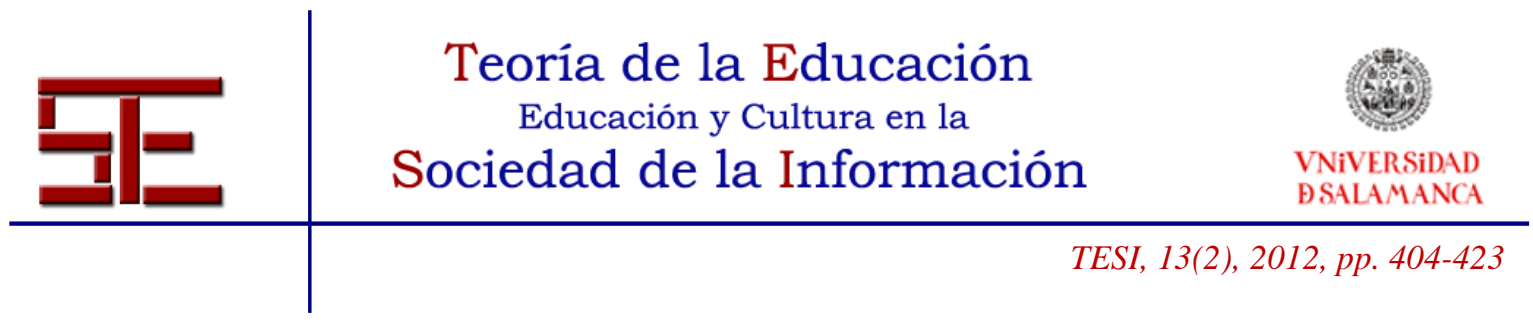

\section{BIBLIOGRAFÍA}

Area, M. (2009). Las redes sociales en internet como espacios para la formación del profesorado. Razón y palabra, 63. Extraído el 5 octubre, 2010 de http://www.razonypalabra.org.mx.

Badia, A. \& Monereo, C. (2005). Aprender a aprender a través de Internet. En C. Monereo (Coord.) et al., Internet y competencias básicas. Aprender a colaborar, a comunicarse, a participar, a aprender (pp. 51-71). Barcelona: Graó.

Barkley, E. F.; Cross, K. P. \& Mayor, C. H. (2007). Técnicas de aprendizaje colaborativo. Madrid: Morata.

Bolívar, A. (2008). El discurso de las competencias en España: educación básica y educación superior. REDU. Revista de Docencia Universitaria, 6 (2). Extraído en 13 mayo, $2011 \mathrm{de}$ http://www.redu.m.es/Red_U/m2.

Castells, M. (1999). La era de la Información. Economía, Sociedad y Cultura. La Sociedad Red. Madrid: Alianza.

Coll, C. et al. (2007). Currículum i ciutadania. El què i el per a qué en l'educació escolar. Barcelona: Fundació Jaume Bofill.

Coll, C., Bustos, A. \& Engel, A. (2007). Configuración y evolución de la comunidad virtual mi-pe/dipe: retos y dificultades. Revista Electrónica de la Educación: Educación y Cultura en la Sociedad de la Información, 8 (3). Extraído el 3 septiembre, 2009 de http://campus.usal.es/ teoriaeducacion/rev_numero_08_03/n8_03_coll_bustos_engel.pdf.

De Miguel, M. (2005). Cambio de paradigma metodológico en la educación superior. Cuadernos de Integración Europea, 2, 6-27. Extraído el 2 de junio, 2011 de http://www.cuadernosie.info.

Díaz-Aguado, M. J. (2003). Educación intercultural y aprendizaje cooperativo. Madrid: Pirámide.

Echeverría, J. (2000). Educación y Tecnología Telemáticas. Revista Iberoamericana de Educación, 24, 17-36.

Garmendia, M. et al. (2011). Riesgos y seguridad en internet: Los menores españoles en el contexto europeo. Bilbao: Universidad del País Vasco.

Gimeno, J. (2001). Educar y convivir en la sociedad global. Madrid: Morata.

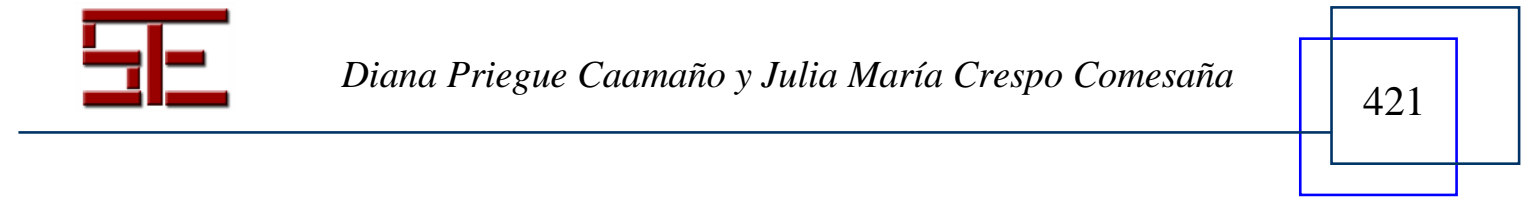




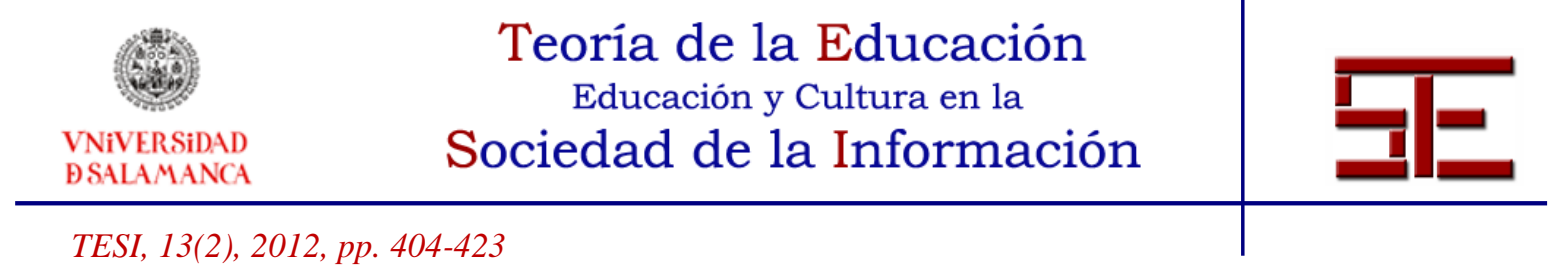

Martínez, F. \& Prendes, M. P. (2003). ¿A dónde va la educación en un mundo de tecnologías? En F. Martínez (Comp.), Redes de comunicación en la enseñanza. Las nuevas perspectivas del trabajo corporativo (pp. 281-300). Barcelona: Paidós.

Martín, M. T. \& Quiroz, C. (2006). Perfil y funciones del educador social. En E. LópezBarajas (Coord.), Estrategias de Formación en el Siglo XXI (pp. 285-316). Barcelona: Ariel.

Mominó, J. M., Sigalés, C. \& Meneses, J. (2007). La escuela en la sociedad red. Internet en la educación Primaria y Secundaria. Barcelona: Ariel.

OCDE (2005). The definition and selection of key competencies. Executive Summary. [Versión electrónica]. Extraído el 8 de septiembre, 2009 de http://www.oecd.org/dataoecd/47/61/35070367.pdf.

Priegue, D. (2009). Soporte tecnológico y gestión educativa de la inmigración. Revista Electrónica Teoría de la Educación: Educación y Cultura en la Sociedad de la Información, 10 (2). Extraído el 15 de septiembre, 2011 de http://campus.usal.es/ teoriaeducacion/rev_numero_10_02/n10_02_priegue.pdf.

Revuelta, F. \& Pérez, L. (2009). Interactividad en los entornos de formación on-line. Barcelona: Editorial UOC.

Rogoff, B. (1993). Aprendices del pensamiento. El desarrollo cognitivo en el contexto social. Barcelona: Paidós.

Santos, M. A. \& Lorenzo, M $^{\mathrm{a}}$ M. (2005). Promoting interculturality in Spain: assessing the use of the Jigsaw classroom method. Intercultural Education, 16 (3), 293-301.

_ (2009). A educación para a cidadanía e os profesores. Visión e desafío. Vigo: Xerais.

Santos, M. A.; Lorenzo, M M. \& Priegue, D. (2009). Aprendizaje cooperativo: práctica pedagógica para el desarrollo escolar y cultural. Magis, Revista Internacional de Investigación en Educación, 1(2), 289-304.

Slavin, R. E. (1999). Aprendizaje cooperativo. Teoría, investigación y práctica. Buenos Aires: Aique.

Tubela, I. \& Vilaseca J. (2005). Sociedad del conocimiento, cómo cambia el mundo ante nuestros ojos. Barcelona: UOC.

Vinagre, M. (2010). Teoría y práctica del aprendizaje colaborativo asistido por ordenador. Madrid: Síntesis.

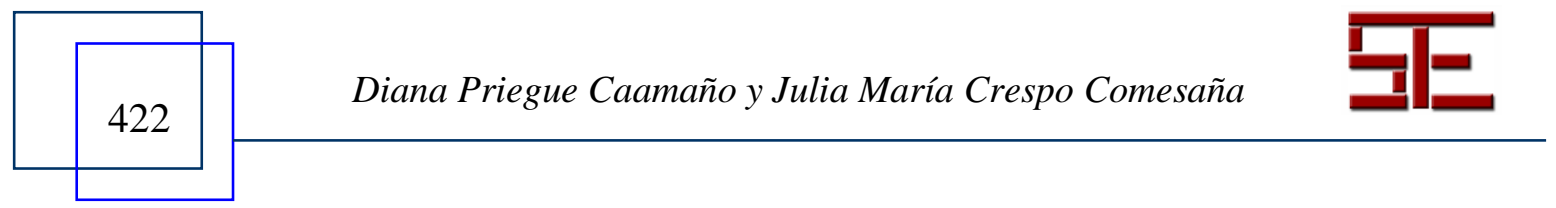




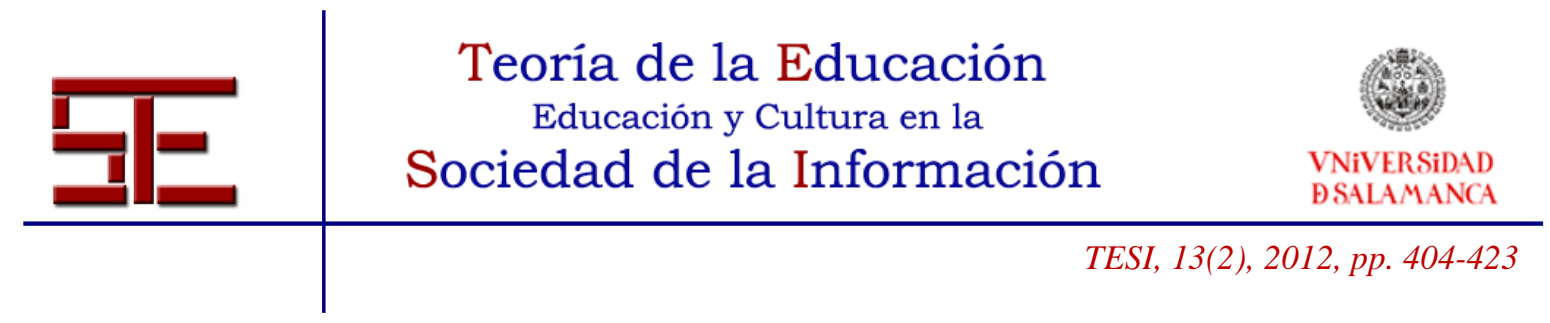

Para citar el presente artículo puede utilizar la siguiente referencia:

Priegue Caamaño, D. y Crespo Comesaña, J. M. (2012). El potencial pedagógico de la tecnología: Desarrollar competencias y favorecer la autonomía y la responsabilidad en el alumnado. Revista Teoría de la Educación: Educación y Cultura en la Sociedad de la Información. 13(2), 404-422 [Fecha de consulta: dd/mm/aaaa].

http://campus.usal.es/ revistas_trabajo/index.php/revistatesi/article/view/9016/9260

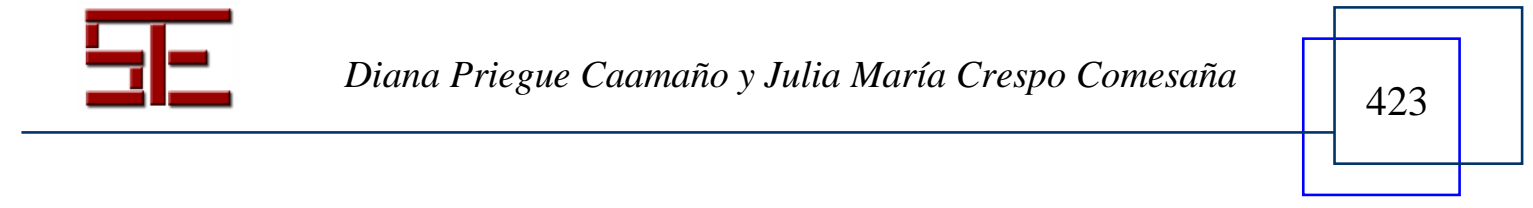

